\title{
Plasma adiponectin levels predict cardiovascular events in the observational Arita Cohort Study in Japan: the importance of the plasma adiponectin levels
}

\author{
Chun-Yen Chen ${ }^{1,2,3}$, Masanori Asakura ${ }^{1}$, Hiroshi Asanuma ${ }^{1}$, Takuya Hasegawa ${ }^{1}$, Jun Tanaka ${ }^{1}$, Norihisa Toh ${ }^{1}$, \\ Kyung-Duk Min ${ }^{1}$, Hideaki Kanzaki ${ }^{1}$, Hiroyuki Takahama ${ }^{1}$, Makoto Amaki ${ }^{1}$, Yumi Itoh ${ }^{4}$, Go Ichien ${ }^{4}$, \\ Yoko Okumoto $^{5}$, Toru Funahashi ${ }^{6}$, Jiyoong Kim $^{1}$ and Masafumi Kitakaze ${ }^{1}$
}

As the plasma level of adiponectin is related to metabolic syndrome and cardiovascular events, a low plasma adiponectin level may either cause or trigger cardiovascular disorders. The purpose of this study was to determine whether a low adiponectin level contributes to cardiovascular events, and to investigate the factors influencing adiponectin in the Japanese Arita-cho cohort study.We followed about 2000 subjects in Arita-cho, Saga, Japan as a cohort study, and we enrolled 637 subjects (205 men; $65.1 \pm 8.3$ years old) who participated in annual health checks from 2005 to 2008 and underwent measurement of the plasma adiponectin level and an oral glucose tolerance test. We monitored the incidence of cardiovascular or cerebrovascular events in these subjects until the end of 2010, discontinuing follow-up at 3 years after the start of enrollment. Subjects with low plasma adiponectin levels $\left(<10.5 \mathrm{ng} \mathrm{m}^{-1}\right)$ had a higher incidence of newly diagnosed cardiovascular diseases such as acute heart failure or acute myocardial infarction than those with high plasma adiponectin levels $\left(\geqslant 10.5 \mathrm{ng} \mathrm{ml}^{-1}\right)$ over an average of 2.95 years of follow-up. Multivariate analysis showed that the adiponectin level was predicted by the following parameters in all subjects: age $(\beta=0.16)$, male gender $(\beta=-0.267)$, homeostasis model assessment of insulin resistance $(\beta=-0.140)$ and the plasma levels of high-density lipoprotein cholesterol $(\beta=0.104)$, uric acid $(\beta=-0.13)$, triglycerides $(\beta=-0.169)$ and brain natriuretic peptide $(\beta=0.151)$. The difference in plasma glucose before and 120 min after the intake of a 75-g glucose load did not influence the plasma adiponectin level. The plasma adiponectin level is useful for predicting cardiovascular events, and is a measure of the risk of lifestyle-related diseases.

Hypertension Research (2012) 35, 843-848; doi:10.1038/hr.2012.42; published online 5 April 2012

Keywords: adiponectin; myocardial infarction; stroke

\section{INTRODUCTION}

Adiponectin is a protein that is secreted exclusively by adipose tissue and contributes to the regulation of lipid and glucose metabolism. Adiponectin is also reported to have anti-inflammatory and antiatherosclerogenic effects ${ }^{1,2}$ in addition to its influence on insulin sensitivity and hepatic gluconeogenesis. ${ }^{3,4}$ Such reports have led to the concept that a low plasma adiponectin level could predict the incidence of vascular events. However, there have been few prospective studies of plasma adiponectin levels and coronary artery disease $(\mathrm{CAD})$ in healthy populations, and the results obtained have been inconclusive. The British Women's Heart and Health Study found no association between the plasma adiponectin level and new-onset CAD during 4 years of follow-up. ${ }^{5}$ In older Dutch subjects, a high baseline plasma adiponectin level was associated with increased 15 -year mortality. ${ }^{6}$ In young survivors ( $<60$ years of age) following a first myocardial infarction, however, a low plasma adiponectin level was associated with recurrent infarction. ${ }^{7}$ Indeed, hypoadiponectinemia has usually been recognized as a risk factor for $C A D^{8-10}$ and the adiponectin level was linked to the severity of heart failure in our previous study. ${ }^{11}$ Taken together, it seems that the plasma adiponectin level may influence cardiovascular or cerebrovascular events but not decisively, because the adiponectin level varies in relation to gender, race and the presence or absence of lifestyle-related disease.

${ }^{1}$ Department of Cardiovascular Medicine, National Cerebral and Cardiovascular Center, Suita, Japan; ${ }^{2}$ Cardiovascular Division, Department of Internal Medicine, Mackay Memorial Hospital, Taipei, Taiwan; ${ }^{3}$ Department of Nursing, Mackay Medicine, Nursing and Management College, Taipei, Taiwan; ${ }^{4}$ HuBit genomix, Inc., Tokyo, Japan; ${ }^{5}$ Department of Health and Welfare, Arita-Town Office, Nagasaki, Japan and ${ }^{6}$ Department of Metabolic Medicine, Graduate School of Medicine, Osaka University, Suita, Japan. Correspondence: Dr M Kitakaze, Department of Cardiovascular Medicine, National Cerebral and Cardiovascular Center, 5-7-1 Fujishirodai, Suita 565-8565, Japan E-mail: kitakaze@zf6.so-net.ne.jp

Received 22 December 2011; revised 24 January 2012; accepted 14 February 2012; published online 5 April 2012 
Therefore, we investigated the predictive value of the plasma adiponectin level for cardiovascular or cerebrovascular disease, and explored factors that influence adiponectin in a cohort study performed in Arita-cho (Saga, Japan). As adiponectin is closely related to the pathophysiology of diabetes mellitus, we particularly investigated the influence of insulin resistance, and that of the glucose and insulin levels after the oral glucose tolerance test (OGTT), on the plasma adiponectin level.

\section{METHODS}

The study was conducted in accordance with the Declaration of Helsinki and was approved by the ethics committees of the National Cerebral and Cardiovascular Center and Arita-cho. Written informed consent was obtained from each subject before participation in the study.

\section{Study population}

The study population included participants in the health check program of Arita-cho (Saga, Japan) from 2005 to 2008 (the Arita-cho cohort Study). Participants who underwent an OGTT were included, but those who had cardiovascular and/or cerebrovascular disease at baseline were excluded from follow-up.

We enrolled 637 of the more than 2000 subjects who participated in the Arita-cho cohort study. The mean age, systolic/diastolic blood pressure (BP) and heart rate of the men $(n=205)$ and women $(n=432)$ was $66.4 \pm 8.2$ and $65.1 \pm 8.4$ years, $134.4 \pm 18.0 / 82.6 \pm 10.8$ and $129.7 \pm 20.0 \mathrm{~mm}$ $\mathrm{Hg} / 78.8 \pm 10.2 \mathrm{~mm} \mathrm{Hg}$ and $63.3 \pm 10.0$ and $66.1 \pm 10.1$ per min, respectively.

\section{Laboratory tests}

Blood was collected from each participant at least $10 \mathrm{~h}$ after the last food intake to measure the plasma levels of adiponectin, fasting plasma glucose, total cholesterol, triglycerides (TG), high-density lipoprotein cholesterol (HDL-C) and brain natriuretic peptide (BNP). The height, body weight and waist circumference of all participants were also measured. The OGTT was performed after a 10-h overnight fast. Each participant ingested a solution containing $75 \mathrm{~g}$ of dextrose, and venous blood samples were obtained at 0,30 , 60, 90 and $120 \mathrm{~min}$ for determination of the plasma glucose level, whereas plasma insulin levels were measured at 0 and $120 \mathrm{~min}$. Then $\Delta$ insulin was calculated as the difference between the baseline and the 2-h insulin values, whereas $\Delta \mathrm{BG}$ ( $\Delta$ blood glucose) was calculated as the difference between the baseline and the 2-h plasma glucose values.

The plasma concentration of adiponectin was measured by an immunoradiometric assay and the plasma concentration of BNP was measured with a commercial kit immunoradiometric assay for human BNP (Shionoria; Shionogi, Osaka, Japan). The insulin resistance index was determined by the homeostasis model assessment of insulin resistance (HOMA-IR) method.

\section{Cardiovascular and cerebrovascular events}

Information on cardiovascular and cerebrovascular diseases was obtained from a standardized questionnaire at baseline and at the annual health checks. If a subject provided information that suggested the possibility of new-onset cardiovascular or cerebrovascular disease, we obtained confirmation from the clinic or hospital where the participant had consulted a cardiologist or neurologist. Diagnosis of new cardiovascular or cerebrovascular disease was defined as the study endpoint during follow-up. Cardiovascular events were defined as hospitalization or death due to heart failure or else the occurrence of acute myocardial infarction. Cerebrovascular events were defined as hospitalization or death due to stroke. For participants without cardiovascular or cerebrovascular events, the final date of follow-up was the date of last contact and follow-up was discontinued at 3 years after enrollment.

\section{Statistical Analysis}

Results are expressed as the mean \pm s.d. or as percentages. Analysis of variance was employed for continuous variables and the $\chi^{2}$-test was used for categorical data to compare differences between groups. Tukey's test was used for post-hoc analysis if analysis of variance revealed a statistically significant difference.
For variables that did not show a normal distribution, including TG, HOMAIR, BNP and adiponectin, the data were transformed into natural logarithmic values before statistical analysis. Multivariate analysis was performed to identify independent predictors. Gender-specific multivariate linear regression models were used to identify the associations that remained significant after adjustment for other variables. Cardiovascular and cerebrovascular event-free curves were drawn by the Kaplan-Meier method and then were compared by the log-rank test. All analyses were performed with SPSS software (SPSS version 12.0, Chicago, IL, USA), and $P<0.05$ was considered statistically significant.

\section{RESULTS}

Among 637 subjects, 384 participants without history of either cardiovascular or cerebrovascular disease enrolled in Arita-cho from 2005 to 2007 completed follow-up. These participants were divided into two groups based on the 50th percentile of plasma adiponectin $\left(10.5 \mathrm{ng} \mathrm{ml}^{-1}\right)$. During the follow-up period, five participants from the low-adiponectin group $\left(<10.5 \mathrm{ng} \mathrm{ml}^{-1}\right)$ suffered from cardiovascular disease (acute decompensated heart failure due to hypertension in three and acute myocardial infarction in two) and four participants developed cerebrovascular disease (cerebral hemorrhage in two and cerebral infarction in two). In the high-adiponectin group $\left(\geqslant 10.5 \mathrm{ng} \mathrm{ml}^{-1}\right)$, two participants suffered from cerebrovascular disease (both had cerebral infarction) and none of the participants developed cardiovascular disease. The cumulative cardiovascular and cerebrovascular event-free rate was lower in the low-adiponectin group (Figure 1). The cardiovascular event-free rate was markedly decreased in the low-adiponectin group (Figure 2), whereas the cerebrovascular event-free rate was similar in both groups (Figure 3).

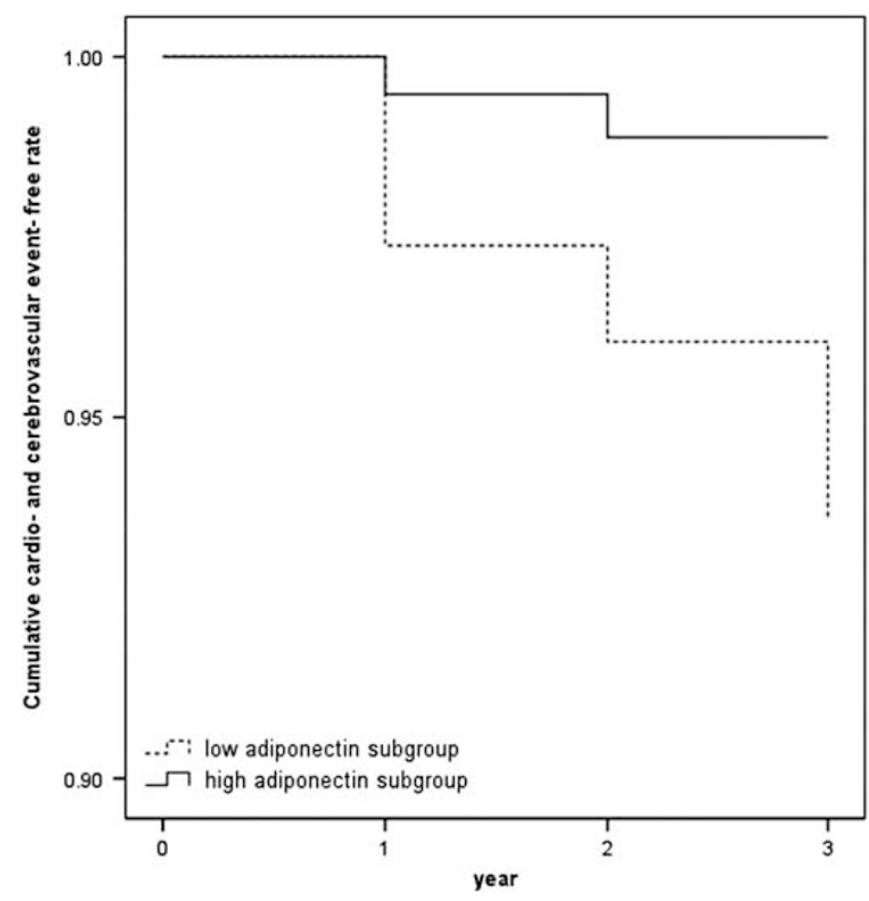

Figure 1 Cardiovascular and cerebrovascular event-free curves obtained with the Kaplan-Meier method in the respective groups divided by adiponectin levels. All participants were divided into two groups according to 50th percentile of adiponectin levels $\left(10.5 \mathrm{ng} \mathrm{ml}^{-1}\right)$. Cumulative cardiovascular and cerebrovascular event-free rates in the low-adiponectin subgroup $(n=191)$ and high-adiponectin subgroup $(n=193)$ were $93.6 \%$ and $98.9 \%$, respectively (log-rank test, $P=0.02$ ). 




Figure 2 Cardiac event-free curves obtained with the Kaplan-Meier method in the respective groups divided by adiponectin levels. All participants were divided into two groups according to 50th percentile of adipoecntin levels $\left(10.5 \mathrm{ng} \mathrm{ml}^{-1}\right)$. Cumulative cardiaovascular event-free rates in the lowadiponectin subgroup $(n=191)$ and high-adiponectin subgroup $(n=193)$ were $96.4 \%$ and $100 \%$, respectively (log-rank test, $P=0.02$ ).

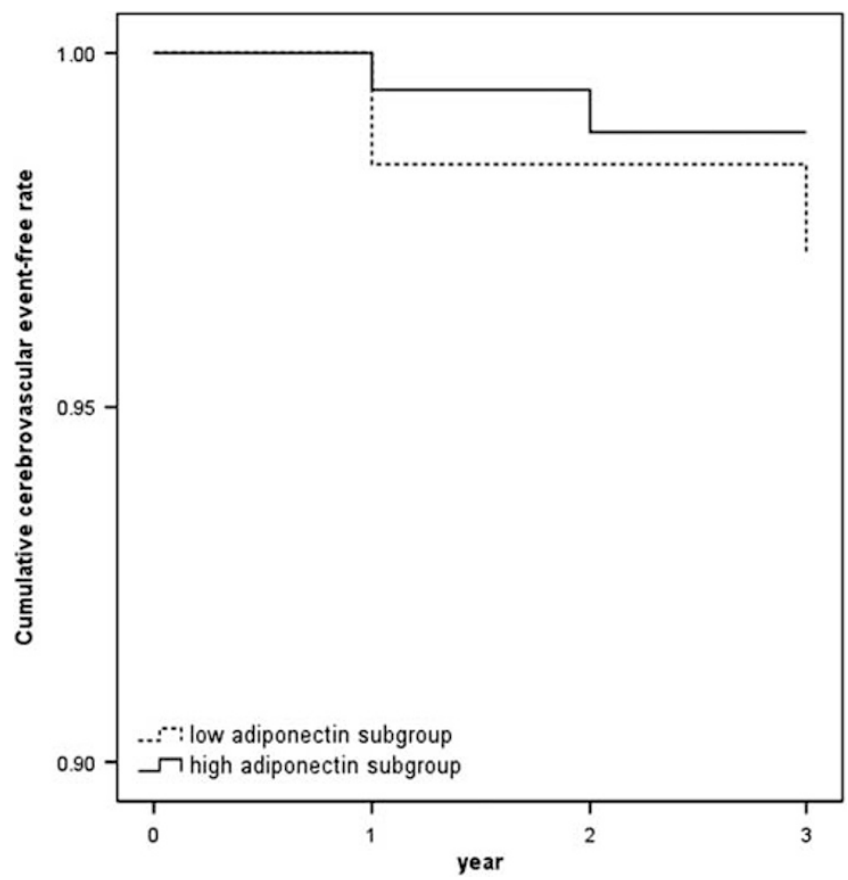

Figure 3 Cerebrovascular event-free curves obtained with the Kaplan-Meier method in the respective groups divided by adiponectin levels. All participants were divided into two groups according to 50th percentile of adipoecntin levels $\left(10.5 \mathrm{ng} \mathrm{ml}^{-1}\right)$. Cumulative cerebrovascular event-free rates in the low-adiponectin subgroup $(n=191)$ and high-adiponectin subgroup ( $n=193$ ) were $97.2 \%$ and $98.9 \%$, respectively (log-rank test, $P=0.37)$
Adiponectin level may be related to BP, and we found that four men in the low-adiponectin group developed hypertension, whereas none of the subjects in the high-adiponectin group developed hypertension, hinting that adiponectin is related to hypertension. However, systolic BP in the low- and high-adiponectin groups were $130.0 \pm 18.6$ and $131.0 \pm 19.1 \mathrm{~mm} \mathrm{Hg}$, respectively $(P=0.40)$; diastolic BPs in the low- and high-adiponectin group were $79.5 \pm 9.5$ and $78.2 \pm 10.6 \mathrm{~mm} \mathrm{Hg}$, respectively $(P=0.26)$. Furthermore, the systolic and diastolic BP during the annual check-up in three subjects who developed heart failure due to hypertension was $130.2 \pm 20.0$ and $81.2 \pm 8.3 \mathrm{mmHg}$, respectively, at examination. The two subjects with a low adiponectin level who had myocardial infarction had no experience of smoking, and did not have diabetes mellitus, but both had hypertension and one of them had dyslipidemia. Our data set did not include data for anticoagulants and anti-hypertensive therapy.

We then investigated factors that influenced the plasma adiponectin level. Table 1 shows the clinical characteristics of all 637 participants from 2005 to 2008 categorized by plasma adiponectin quartiles (first quartile, $<6.66 \mathrm{ng} \mathrm{ml}^{-1}$; second quartile, $\geqslant 6.66 \mathrm{ng} \mathrm{ml}^{-1}$ and $<9.80 \mathrm{ng} \mathrm{ml}^{-1}$; third quartile, $\geqslant 9.80 \mathrm{ng} \mathrm{ml}^{-1}$ and $<14.28 \mathrm{ng} \mathrm{ml}^{-1}$; fourth quartile: $\geqslant 14.28 \mathrm{ng} \mathrm{ml}^{-1}$ ). There were no significant differences of $\mathrm{HbA}_{1 \mathrm{c}}$ among the four quartiles. The fourth quartile was older than the other three quartiles, and plasma levels of HDL-C and BNP were significantly higher in the fourth quartile than in the other three. The fourth quartile had lower BMI, waist circumference, plasma uric acid, plasma TG, $\Delta$ insulin, $\Delta$ BG, HOMA-IR and percentage of men than the other three quartiles. The first quartile had higher fasting BG levels and a higher prevalence of diabetes mellitus than the other three quartiles. In addition, the mean BMI of the four quartiles was below 25. The plasma adiponectin level (Ln adiponectin) was higher in women than in men $(2.42 \pm 0.51$ vs. $1.99 \pm 0.99 ; \quad P<0.0001)$. The plasma adiponectin level was negatively associated with HOMA-IR in women, men and all subjects (Figure 4).

To further clarify the factors that influenced the plasma adiponectin level, multivariate linear regression analysis was performed with plasma adiponectin as the dependent variable. As a result, the age $(\beta=0.16)$, HOMA-IR $(\beta=-0.140)$, male gender $(\beta=-0.267)$ and plasma levels of HDL-C $(\beta=0.104)$, uric acid $(\beta=-0.13)$, TG $(\beta=-0.169)$ and BNP $(\beta=0.151)$ were significant predictors of the plasma adiponectin level in all participants (Table 2). Because women have higher plasma adiponectin levels than men, we separately investigated the determinants of adiponectin in men and women. We found that the age $(\beta=0.153)$, HOMA-IR $(\beta=-0.208)$ and plasma $\operatorname{BNP}(\beta=0.149)$ were independently associated with the plasma adiponectin level in men, whereas the age $(\beta=0.194)$, $\Delta$ insulin $(\beta=-0.152)$, HOMA-IR $(\beta=-0.131)$ and plasma levels of HDL-C $(\beta=0.129)$, uric acid $(\beta=-0.119)$, TG $(\beta=-0.179)$ and BNP $(\beta=0.161)$ were independently associated with adiponectin in women. Thus, the present study demonstrated that HOMA-IR, but not $\Delta \mathrm{BG}$, is associated with a decrease of the plasma adiponectin level.

\section{DISCUSSION}

In the present study, we found that subjects with low plasma adiponectin levels had a higher incidence of cardiovascular diseases, such as heart failure and myocardial infarction, than subjects with high plasma adiponectin levels. On the other hand, we found that age, insulin resistance and the plasma levels of HDL-C, uric acid, TG and BNP were independent predictors of the plasma adiponectin level. 
Table 1 Comparison of characteristics by quartiles of serum adiponectin levels in all subjects

\begin{tabular}{|c|c|c|c|c|c|}
\hline & First quartile $(\mathrm{n}=159)$ & Second quartile $(n=159)$ & Third quartile $(\mathrm{n}=160)$ & Fourth quartile $(\mathrm{n}=159)$ & P-value \\
\hline BMI $\left(\mathrm{kg} \mathrm{m}^{-2}\right)$ & $23.4 \pm 2.6$ & $23.6 \pm 3.1$ & $22.5 \pm 2.8^{b, d}$ & $21.4 \pm 3.1^{c, e, f}$ & $<0.0001$ \\
\hline $\mathrm{HbA1c}(\%)$ & $5.3 \pm 0.4$ & $5.4 \pm 0.6$ & $5.3 \pm 0.3$ & $5.3 \pm 0.4$ & 0.43 \\
\hline HDL-C (mg dl $\left.{ }^{-1}\right)$ & $55.1 \pm 13.6$ & $58.8 \pm 14.0$ & $60.5 \pm 14.1^{b}$ & $68.3 \pm 15.7^{c, e, f}$ & $<0.0001$ \\
\hline Uric acid $\left(\mathrm{mg} \mathrm{dl}^{-1}\right)$ & $5.8 \pm 1.4$ & $5.1 \pm 1.2^{\mathrm{a}}$ & $4.6 \pm 1.2^{b, d}$ & $4.5 \pm 1.1^{\mathrm{c}, \mathrm{e}}$ & $<0.0001$ \\
\hline$\Delta$ insulin $\left(\mu \cup \mathrm{ml}^{-1}\right)$ & $50.7 \pm 39.8$ & $58.7 \pm 53.6$ & $40.1 \pm 30.3^{d}$ & $30.9 \pm 23.8^{\mathrm{c}, \mathrm{e}}$ & $<0.0001$ \\
\hline$\Delta \mathrm{BG}\left(\mathrm{mg} \mathrm{dl}^{-1}\right)$ & $48.9 \pm 43.7$ & $47.5 \pm 44.1$ & $36.0 \pm 36.8^{b}$ & $33.4 \pm 45.1^{\mathrm{c}, \mathrm{e}}$ & 0.001 \\
\hline Fasting glucose (mg dl $\left.{ }^{-1}\right)$ & $97.1 \pm 11.4$ & $96.2 \pm 10.4$ & $92.8 \pm 8.2^{\mathrm{b}, \mathrm{d}}$ & $93.1 \pm \pm^{c, e}$ & $<0.0001$ \\
\hline Fasting insulin $\left(\mu \cup \mathrm{ml}^{-1}\right)$ & $5.8 \pm 4.6$ & $5.7 \pm 4.1$ & $4.4 \pm 2.3^{\mathrm{b}, \mathrm{d}}$ & $3.6 \pm 1.9^{\mathrm{c}, \mathrm{e}}$ & $<0.0001$ \\
\hline Ln HOMA-IR & $0.13 \pm 0.66$ & $0.11 \pm 0.64$ & $-0.11 \pm 0.55^{\mathrm{b}, \mathrm{d}}$ & $-0.35 \pm 0.60^{c, e, f}$ & $<0.0001$ \\
\hline $\operatorname{Ln} B N P\left(\mathrm{pg} \mathrm{ml}^{-1}\right)$ & $2.7 \pm 0.7$ & $2.9 \pm 0.8$ & $3.1 \pm 0.7^{b}$ & $3.4 \pm 0.8^{\mathrm{c}, \mathrm{e}, \mathrm{f}}$ & $<0.0001$ \\
\hline
\end{tabular}

Abbreviations: BG, blood glucose; BMI, body mass index; BNP, brain natriuretic peptide; DM, diabetes mellitus; HDL-C, high-density lipoprotein cholesterol; HOMA-IR, homeostasis model assessment-insulin resistance; TG, triglyceride.

Adiponectin: First quartile, $<6.66$; second quartile, $\geqslant 6.66$ and $<9.80$; third quartile, $\geqslant 9.80$ and $<14.28$; fourth quartile: $\geqslant 14.28$.

aFirst vs. second quartile.

bFirst vs. third quartile.

${ }^{c}$ First vs. fourth quartile.

${ }^{d}$ Second vs. third quartile.

esecond vs. fourth quartile.

fThird vs. fourth quartile.

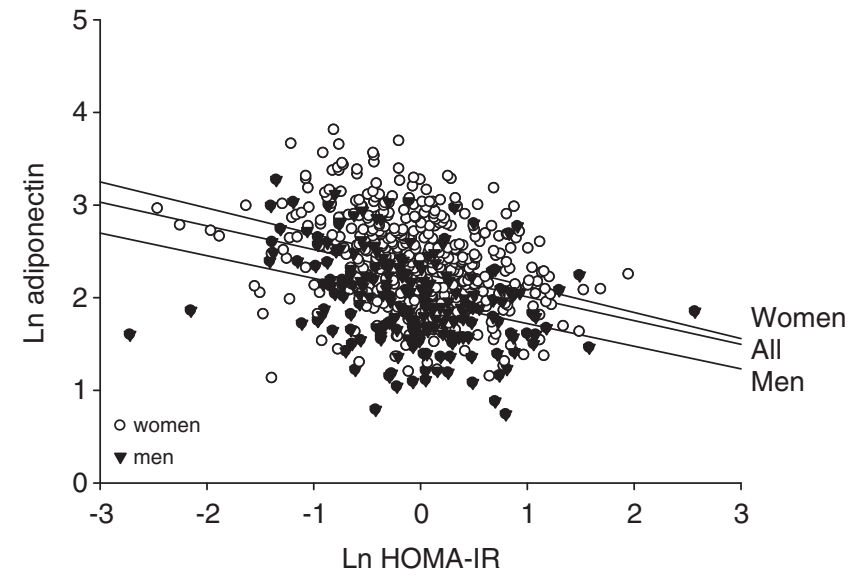

All: Pearson correlation coefficient $=-0.31 ; p<0.001$;

Men: Pearson correlation coefficient $=-0.34 ; p<0.001$;

Women: Pearson correlation coefficient $=-0.35 ; p<0.001$

Figure 4 Scatter plot of the association between natural log-transformed plasma adiponectin levels and homeostasis model assessment-insulin resistance (HOMA-IR) in healthy subjects. Lines indicate the regression lines.

Furthermore, we showed that the glucose spike during the OGTT was not related to the plasma adiponectin level.

What is the role of adiponectin in cardiovascular and cerebrovascular events? First, a low adiponectin level was not associated with cerebral hemorrhage or infarction after adjusting for other cardiovascular risk factors in the JMS cohort study that was performed in 12 rural districts in Japan, ${ }^{12}$ and that the finding corresponds with the present result that the plasma adiponectin level is not related to cerebrovascular events. Second, Persson et al. ${ }^{7}$ reported that low plasma adiponectin levels are associated with myocardial infarction in individuals below the age of 60 years, and Nakamura et al. ${ }^{10}$ found that hypoadiponectinemia may increase the risk of acute coronary syndrome. Furthermore, in a study of Japanese men with CAD, patients with acute coronary syndrome had lower adiponectin levels than stable CAD patients, whereas patients with multiple complex lesions had significantly lower adiponectin levels than those with solitary complex lesions. ${ }^{13}$ Thus, low adiponectin levels may be related to vulnerability to coronary atherosclerosis, which was also confirmed by the results of the present study. An important new finding of the present study is that adiponectin levels were monitored in a cohort and cardiovascular events were assessed prospectively.In our study, the low adiponectin level predicted cardiovascular events but not cerebrovascular events. The vascular or endothelial response to adiponectin may differ between the coronary and cerebral artery; however, the precise molecular mechanism underlying this difference remained unclear. Further basic and epidemiological studies are needed to elucidate the lack of a protective effect of adiponectin against stroke.

With regard to the vulnerability of coronary plaques, hypertension is believed to be one of the most important factors. Iwashima et al. ${ }^{14}$ reported that the plasma adiponectin levels were lower in hypertensive subjects in a hospital-based study. In addition, two prospective Asian studies have shown that hypoadiponectinemia is associated with incident hypertension. Chow et al. ${ }^{15}$ conducted a 5 -year prospective study to examine the association between adiponectin and hypertension in a nondiabetic Chinese cohort. From health insurance data, 391 healthy Japanese men were followed for a period of 6 years in another study, during which 45 of them developed hypertension. ${ }^{16}$ Our results were partially consistent with those of these studies, because four men in the low-adiponectin group developed hypertension, whereas none of the subjects in the highadiponectin group developed hypertension. However, BP was not linked to the adiponectin levels, although in the present study we did 
Table 2 Multivariate linear regression analysis of independent determinants of Ln adiponectin

\begin{tabular}{|c|c|c|c|c|c|c|}
\hline & \multicolumn{2}{|c|}{$A / /(\mathrm{n}=637)$} & \multicolumn{2}{|c|}{ Men $(n=205)$} & \multicolumn{2}{|c|}{ Women $(n=432)$} \\
\hline & $\beta$ & P-value & $\beta$ & $\mathrm{P}$-value & $\beta$ & P-value \\
\hline Age (years) & 0.160 & $<0.001$ & 0.153 & 0.03 & 0.194 & $<0.001$ \\
\hline BMI $\left(\mathrm{kg} \mathrm{m}^{-2}\right)$ & 0.018 & 0.75 & 0.007 & 0.96 & 0.034 & 0.63 \\
\hline Waist circumference $(\mathrm{cm})$ & -0.092 & 0.11 & -0.134 & 0.30 & -0.093 & 0.19 \\
\hline $\mathrm{HbAlc}(\%)$ & -0.015 & 0.66 & 0.088 & 0.21 & -0.067 & 0.12 \\
\hline HDL-C (mg dl-1) & 0.104 & 0.005 & 0.100 & 0.16 & 0.129 & 0.007 \\
\hline Uric acid (mg dl-1) & -0.130 & 0.001 & -0.126 & 0.06 & -0.119 & 0.006 \\
\hline Ln TG (mg dl $\left.{ }^{-1}\right)$ & -0.169 & $<0.001$ & -0.151 & 0.05 & -0.179 & $<0.001$ \\
\hline$\Delta B G\left(\mathrm{mg} \mathrm{dl}^{-1}\right)$ & 0.014 & 0.77 & -0.118 & 0.27 & 0.068 & 0.25 \\
\hline$\Delta$ insulin $\left(\mu \cup \mathrm{ml}^{-1}\right)$ & -0.062 & 0.12 & 0.127 & 0.10 & -0.152 & 0.004 \\
\hline Ln HOMA-IR & -0.140 & 0.001 & -0.208 & 0.009 & -0.131 & 0.02 \\
\hline Ln BNP (pg ml-1) & 0.151 & $<0.001$ & 0.149 & 0.03 & 0.161 & $<0.001$ \\
\hline Diagnosed DM & -0.052 & 0.25 & -0.001 & 0.99 & -0.067 & 0.22 \\
\hline Gender (men) & -0.267 & $<0.001$ & & & & \\
\hline
\end{tabular}

Abbreviations: BG, blood glucose; BMI, body mass index; BNP, brain natriuretic peptide; DM, diabetes mellitus; HDL-C, high-density lipoprotein cholesterol; HOMA-IR, homeostasis model assessment-insulin resistance; TG, triglyceride.

All: adjusted $\mathrm{R}^{2}: 0.38$; Men: adjusted $\mathrm{R}^{2}: 0.26$; Women: adjusted $\mathrm{R}^{2}: 0.30 ; \beta$ : standardized regression coefficient.

not have information about the anti-hypertensive drugs used. Indeed, in the Copenhagen City Heart Study, the plasma adiponectin level was not an independent predictor of new-onset hypertension, ${ }^{17}$ so there may be a racial difference with regard to the influence of adiponectin on hypertension. The linkage between hypertension and the plasma adiponectin level is not conclusive in the present study.

The next issue is the mechanisms by which a low adiponectin level can be linked to cardiovascular disease. Ouchi et al. ${ }^{18}$ reported that hypoadiponectinemia is associated with impaired endotheliumdependent vasorelaxation, and endothelial dysfunction is an important feature of the early stages of atherosclerosis and hypertension. ${ }^{19}$ In Apo E-deficient mice, an increase in the plasma adiponectin level suppressed the progression of atherosclerotic lesions by attenuating endothelial inflammation and transformation of macrophages to foam cells in vivo. ${ }^{20,21}$ Furthermore, a low adiponectin level and/or impaired endothelial dysfunction are associated with the onset of pressure-overload heart failure. ${ }^{22}$ whereas impaired endothelial dysfunction is related to hypertension and diastolic dysfunction, ${ }^{23}$ which may explain the high incidence of acute heart failure in patients who have hypertension as well as those with acute coronary syndrome. Therefore, a low plasma adiponectin level may provoke coronary and myocardial changes that culminate in cardiovascular disease.

Because a low adiponectin level was associated with an increased incidence of cardiovascular disease, we investigated the determinants of adiponectin among participants who underwent the OGTT, because we hypothesized that the glucose spike during this test would be related to the plasma adiponectin level. We found that the age, gender, insulin resistance and plasma levels of TG, HDL-C, BNP and uric acid influenced the adiponectin level in all participants, which agreed with previous reports. ${ }^{5,24,25}$ However, we found that the glucose spike during the OGTT did not affect the plasma adiponectin level, although HOMR-IR (which represents insulin resistance) had an influence on adiponectin. The present results suggest that adiponectin may have a regulatory role in insulin secretion. However, this relationship between insulin secretion and the plasma adiponectin level was found in women, but not in men, in the present study. Therefore, the plasma adiponectin level may be influenced by the pattern of abnormal glucose metabolism, with the most important factor being the level of insulin resistance rather than the glucose spike or the amount of insulin secretion. Thus, impaired signal transduction following insulin receptor activation may be linked to the plasma adiponectin level.

Overall, the results of our study were consistent with those of other population-based studies. The plasma adiponectin level was inversely associated with insulin resistance, plasma TG and plasma uric acid, whereas it was positively correlated with HDL-C and BNP levels. ${ }^{4,5,24,26}$ The adiponectin levels increase in patients with myocardial dysfunction in our study, although adiponectin is protective against heart failure because adiponectin attenuates cardiac hypertrophy. ${ }^{22,27}$ The plasma adiponectin level may be upregulated to compensate for cardiovascular damage because BNP can modulate adiponectin signaling via a cyclic guanosine $5^{\prime}$-monophosphate-mediated pathway in human adipocytes. ${ }^{28}$ That may be one of the explanations for the positive correlation between the plasma adiponectin and BNP.

However, several limitations of the present study should be considered. The study population was only of moderate size and the percentage of men was relatively low. This cohort study focused on rural residents, who may differ in various ways from urban residents. Moreover, the follow-up period was relatively short. Nevertheless, we demonstrated that the plasma adiponectin level is tightly related to cardiovascular events, suggesting that adiponectin is a potential biomarker for predicting cardiovascular events, although further studies are required for confirmation.

\section{CONFLICT OF INTEREST}

The authors declare no conflict of interest.

\section{ACKNOWLEDGEMENTS}

This work was supported by Grants-in-aids from the Japanese Ministry of Health, Labor and Welfare, and the Japanese Ministry of Education, Culture, Sports, Science and Technology and by Grants from the Japan Heart Foundation, and the Japan Cardiovascular Research Foundation. 
1 Ouchi N, Kihara S, Arita Y, Nishida M, Matsuyama A, Okamoto Y, Ishigami M, Kuriyama H, Kishida K, Nishizawa H, Hotta K, Muraguchi M, Ohmoto Y, Yamashita S, Funahashi T, Matsuzawa Y. Adipocyte-derived plasma protein, adiponectin, suppresses lipid accumulation and class $A$ scavenger receptor expression in human monocytederived macrophages. Circulation 2001; 103: 1057-1063.

2 Maahs DM, Ogden LG, Kinney GL, Wadwa P, Snell-Bergeon JK, Dabelea D, Hokanson JE, Ehrlich J, Eckel RH, Rewers M. Low plasma adiponectin levels predict progression of coronary artery calcification. Circulation 2005; 111: 747-753.

3 Trujillo ME, Scherer PE. Adiponectin- journey from an adipocyte secretory protein to biomarker of the metabolic syndrome. J Int Med 2005; 257: 167-175.

4 Tschritter O, Fritsche A, Thamer C, Haap M, Shirkavand F, Rahe S, Staiger H, Maerker E, Häring H, Stumvoll M. Plasma adiponectin concentrations predict insulin sensitivity of both glucose and lipid metabolism. Diabetes 2003; 52: 239-243.

5 Lawlor DA, Davey Smith G, Ebrahim S, Thompson C, Sattar N. Plasma adiponectin levels are associated with insulin resistance, but do not predict future risk of coronary heart disease in women. J Clin Endocrinol Metab 2005; 90: 5677-5683.

6 Dekker JM, Funahashi T, Nijpels G, Pilz S, Stehouwer CD, Snijder MB, Bouter LM, Matsuzawa Y, Shimomura I, Heine RJ. Prognostic value of adiponectin for cardiovascular disease and mortality. J Clin Endocrinol Metab 2008; 93: 1489-1496.

7 Persson J, Lindberg K, Gustafsson TP, Eriksson P, Paulsson-Berne G, Lundman P. Low plasma adiponectin concentration is associated with myocardial infarction in young individuals. J Intern Med 2010; 268: 194-205.

8 Kumada M, Kihara S, Sumitsuji S, Kawamoto T, Matsumoto S, Ouchi N, Arita Y, Okamoto Y, Shimomura I, Hiraoka H, Nakamura T, Funahashi T, Matsuzawa Y, Osaka CAD. Study GroupAssociation of hypoadiponectinemia with coronary artery disease in men. Arterioscler Thromb Vasc Biol 2003; 23: 85-89.

9 Hashimoto N, Kanda J, Nakamura T, Horie A, Kurosawa H, Hashimoto T, Sato K, Kushida S, Suzuki M, Yano S, Iwai R, Takahashi H, Yoshida S. Association of hypoadiponectinemia in men with early onset of coronary heart disease and multiple coronary artery stenoses. Metabolism 2006; 55: 1653-1657.

10 Nakamura $Y$, Shimada K, Fukuda D, Horie A, Kurosawa H, Hashimoto T, Sato K, Kushida S, Suzuki M, Yano S, Iwai R, Takahashi H, Yoshida S. Implications of plasma concentrations of adiponectin in patients with coronary artery disease. Heart 2004; 90 528-533.

11 Ohara T, Kim J, Asakura M, Asanuma H, Nakatani S, Hashimura K, Kanzaki H, Funahashi T, Tomoike H, Kitakaze M. Plasma adiponectin is associated with plasma brain natriuretic peptide and cardiac function in healthy subjects. Hypertens Res 2008; 31: 825-831.

12 Matsumoto M, Ishikawa S, Kajii E. Association of adiponectin with cerebrovascular disease: a nested case-control study. Stroke 2008; 39: 323-328.

13 Otsuka F, Sugiyama S, Kojima S, Maruyoshi H, Funahashi T, Matsui K, Sakamoto T, Yoshimura M, Kimura K, Umemura S, Ogawa H. Plasma adiponectin levels are associated with coronary lesion complexity in men with coronary artery disease. $\mathrm{J} \mathrm{Am}$ Coll Cardiol 2006; 48: 1155-1162.

14 Iwashima Y, Katsuya T, Ishikawa K, Ouchi N, Ohishi M, Sugimoto K, Fu Y, Motone M, Yamamoto K, Matsuo A, Ohashi K, Kihara S, Funahashi T, Rakugi H, Matsuzawa Y, Ogihara T. Hypoadiponectinemia is an independent risk factor for hypertension. Hypertension 2004; 43: 1318-1323.

15 Chow WS, Cheung BM, Tso AW, Tso AW, Xu A, Wat NM, Fong CH, Ong LH, Tam S, Tan KC, Janus ED, Lam TH, Lam KS. Hypoadiponectinemia as a predictor for the development of hypertension: a 5-year prospective study. Hypertension 2007; 49 1455-1461.

16 Imatoh T, Miyazaki M, Momose Y, Tanihara S, Une H. Adiponectin levels associated with the development of hypertension: a prospective study. Hypertens Res 2008; $\mathbf{3 1}$ : 229-233.

17 Asferg C, Møgelvang R, Flyvbjerg A, Frystyk J, Jensen JS, Marott JL, Appleyard M, Jensen GB, Jeppesen J. Leptin, not adiponectin, predicts hypertension in the Copenhagen City Heart Study. Am J Hypertens 2010; 23: 327-333.

18 Ouchi N, Ohishi M, Kihara S, Funahashi T, Nakamura T, Nagaretani H, Kumada M, Ohashi K, Okamoto Y, Nishizawa H, Kishida K, Maeda N, Nagasawa A, Kobayashi H, Hiraoka H, Komai N, Kaibe M, Rakugi H, Ogihara T, Matsuzawa Y. Association of hypoadiponectinemia with impaired vasoreactivity. Hypertension 2003; 42: 231-234.

19 Wallace SM, Yasmin, McEniery CM, Mäki-Petäjä KM, Booth AD, Cockcroft JR, Wilkinson IB. Isolated systolic hypertension is characterized by increased aortic stiffness and endothelial dysfunction. Hypertension 2007; 50: 228-233.

20 Okamoto Y, Kihara S, Ouchi N, Nishida M, Arita Y, Kumada M, Ohashi K, Sakai N, Shimomura I, Kobayashi H, Terasaka N, Inaba T, Funahashi T, Matsuzawa Y Adiponectin reduces atherosclerosis in apolipoprotein E-deficient mice. Circulation 2002; 106: 2767-2770.

21 Marso SP, Mehta SK, Frutkin A, House JA, McCrary JR, Kulkarni KR. Low adiponectin levels are associated with atherogenic dyslipidemia and lipid-rich plaque in nondiabetic coronary arteries. Diabetes Care 2008; 31: 989-994.

22 Liao Y, Takashima S, Maeda N, Ouchi N, Komamura K, Shimomura I, Hori M, Matsuzawa Y, Funahashi T, Kitakaze M. Exacerbation of heart failure in adiponectindeficient mice due to impaired regulation of AMPK and glucose metabolism. Cardiovas Res 2005; 671: 705-713.

23 Tsukamoto O, Minamino T, Sanada S, Okada K, Hirata A, Fujita M, Shintani Y, Yulin L, Asano Y, Takashima S, Yamasaki S, Tomoike H, Hori M, Kitakaze M. The antagonism of aldosterone receptor prevents the development of hypertensive heart failure induced by chronic inhibition of nitric oxide synthesis in rats. Cardiovasc Drugs Ther 2006; 20: 93-102.

24 Cnop M, Havel PJ, Utzschneider KM, Carr DB, Sinha MK, Boyko EJ, Retzlaff BM, Knopp RH, Brunzell JD, Kahn SE. Relationship of adiponectin to body fat distribution, insulin sensitivity and plasma lipoproteins: evidence for independent roles of age and sex. Diabetologia 2003; 46: 459-469.

25 Isobe T, Saitoh S, Takagi S, Takeuchi H, Chiba Y, Katoh N, Shimamoto K. Influence of gender, age and renal function on plasma adiponectin level: the Tanno and Sobetsu study. Eur J Endocrinol 2005; 153: 91-98.

26 Matsubara M, Maruoka S, Katayose S. Decreased plasma adiponectin concentrations in women with dyslipidemia. J Clin Endocrinol Metab 2002; 87: 2764-2769.

27 Shibata R, Ouchi N, Ito M, Kihara S, Shiojima I, Pimentel DR, Kumada M, Sato K, Schiekofer S, Ohashi K, Funahashi T, Colucci WS, Walsh SK. Adiponectinmediated modulation of hypertrophic signals in the heart. Nat Med 2004; 10: 1384-1389.

28 Tsukamoto O, Fujita M, Kato M, Yamazaki S, Asano Y, Ogai A, Okazaki H, Asai M, Nagamachi Y, Maeda N, Shintani Y, Minamino T, Asakura M, Kishimoto I, Funahashi T, Tomoike H, Kitakaze M. Natriuretic peptides enhance the production of adiponectin in human adipocytes and in patients with chronic heart failure. J Am Coll Cardiol 2009; 53: 2070-2077. 